\title{
Early Modern Geometries Introduction
}

\author{
Claudia Swan \\ Department of Art History, Northwestern University, Evanston, IL, USA \\ c-swan@northwestern.edu
}

The subject of this special issue is early modern geometries, a plurality of practical and theoretical concerns that animated artistic, scientific, and other pursuits too. There is but one Euclid (c. $325^{-265}$ BCE), the Greek mathematician whose axiomatic geometry of planes and solids gave the rule to measures of number in space well into the modern era. One of the four modes of study that comprised the quadrivium, a curricular model established by Plato, geometry is considered a unit of study, alongside arithmetic, music, and astronomy. ${ }^{1}$ But in the early modern era, there was a geometry for everyone. Appropriately, given the venue in which this collection of papers appears, the various applications of geometrical principles that shaped early modern practices - from geodesics, cartography, and fencing to perspective, mining, and typography - were enabled and driven by the publication of illustrated, practical treatises and the disciplined production of instruments. ${ }^{2}$ The unremitting

1 On curricular reforms and theoretical innovations in sixteenth-century Germany especially among Lutheran scholars, see Jennifer Nelson, Disharmony of the Spheres. The Europe of Holbein's Ambassadors (University Park:The Pennsylvania State University Press, 2019), pp. 26-27 and passim, with prior literature on the relationship between science and theology.

2 "Throughout the sixteenth and seventeenth centuries instrument books (frequently, but not exclusively, written in the vernacular) poured from the European presses, aimed at a wide audience from courtly patrons and gentleman amateur mathematicians, to professional architects, surveyors, and military engineers, not to mention instrument makers themselves." Alexander Marr, "The Production and Distribution of Mutio Oddi's Dello squadro (1625)," in Transmitting Knowledge. Words, Images, and Instruments in Early Modern Europe, edited by Sachiko Kusukawa, Ian Maclean (Oxford: Oxford University Press, 2006), pp. 164-192: 164. Generally, on the rise of the artisan-practitioner, and the spread of scientific knowledge through manuals see the work of Pamela O. Long, esp. her Artisan/Practitioners and the Rise of the New Sciences, 1400-1600 (Corvallis: Oregon State University Press, 2011). On early modern instruments, see Jim Bennett, "Early Modern Mathematical Instruments," Isis, 2011, 102/4:697705. See also Susan Dackerman (ed.), Prints and the Pursuit of Knowledge in Early Modern Europe (New Haven-London: Yale University Press, 2011). 


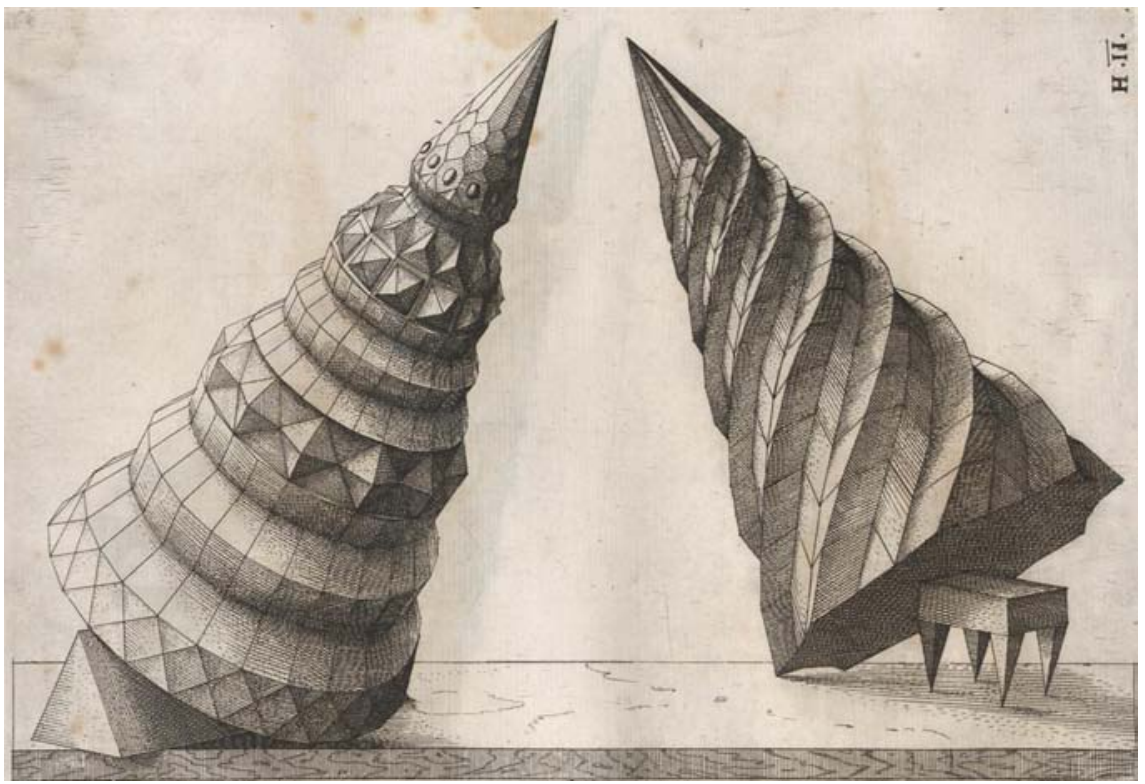

FIGURE 1 Joost Amman, Polyhedral figures, etching $(18 \times 26 \mathrm{~cm})$ in Wenzel Jamnitzer, Perspectiva corporum regularium (Nuremberg: Heußler, 1568)

AVAILABLE AT: HTTPS://DIGITAL.SLUB-DRESDEN.DE/WERKANSICHT/DLF/ 12830/1/ (ACCESSED 26 JULY 2020)

presence of geometrical diagrams in printed manuals on optics, perspective, the stars, fencing, alchemy, mining, and of course geometry for its own sake is mesmerizing (Fig. 1). Geometric diagrams populate all manner of technical and practical texts - Otto van Veen's extraordinary religious abstractions in his Physicae et theologicae conclusiones (1621) no less than the observations by Johannes Kepler on the structure of snow and ice, in De nive sexangular (On the six-cornered snowflake), a lark he penned as a New Year's gift for a friend in $1610-1611{ }^{3}$ Kepler published his Dioptrice in the same year as his meditation on the forms of snowflakes; both treatises depend on geometrical reasoning for their respective demonstrations. To describe the optics of refractive lenses and the workings of the telescope in Dioptrice, Kepler relies on geometric diagrams, even as he does to entirely different ends in the De nive sexangular, where he questions why pomegranate seeds and honeycomb take geometric form. The underlying principles - the Euclidian lingua franca of spatial thinking - were

3 On Vaenius, see Christoph Geissmar, "The Geometrical Order of the World: Otto van Veen's Physicae et theologicae conclusiones," Journal of the Warburg and Courtauld Institutes, 1993, 56:168-182. Johannes Kepler, De nive sexangular (Frankfurt: G. Tambach, 1611). 
consistent, but the applications and the products of early modern geometry were literally all over the map.

For the cosmographer, who measured the heavens and correlated their forms with those of the earth, geometry offered a means to make the known world comprehensible. As Denis E. Cosgrove notes, "the social and technical relations of Renaissance cosmography converged around a growing apprehension of terrestrial, celestial, and representational space as absolute and capable

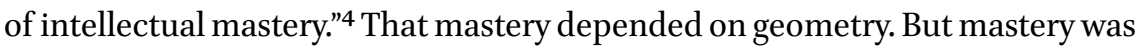
not a given. Leonardo da Vinci's extraordinary notebook sketch known as Vitruvian Man was born of measures the figure assumes and upholds. He is the very embodiment of a geometric order and a canon of proportions. In 1514 the German Renaissance master Albrecht Dürer published a stunning counterpart to Leonardo's geometrical optimism in the form of the darkly compelling allegorical engraving Melencolia I (Fig. 2). Dürer's figuration speaks to a hampered imagination frustrated by the practical, geometric arts, whose instruments she cannot put to use. ${ }^{5}$ Three years before his death, Dürer published Underweysung der Messung (Instructions on measurement) intended, the introduction specifies, "not only for painters, but also for goldsmiths, sculptors, stonemasons, carpenters, and all those for whom using measurement is useful." The 1525 Underweysung der Messung reviews expositions of Euclidean principles as well as applied mathematics, in a discussion and illustration of the structure of a nautilus shell; the makings of a monument; the application of perspective; and other matters too. The intended audience is "everyone desirous of learning about art." The text and its woodcut illustrations - as well as the annotations and insertions in his personal copy, which is preserved - manifest a commitment to make sense of the visual world. ${ }^{6}$ The ambit of the compass offers the comfort of a world of order.

4 Denis E. Cosgrove, "Images of Renaissance Cosmography, 1450-165o," in The History of Cartography, vol. 3, part 1, Cartography in the European Renaissance, edited by David Woodward (Chicago: University of Chicago Press, 2007), pp. 55-98: 55 .

5 On the relationship between Dürer's Vier Bücher von menschlicher Proportion (Four books on human proportion) (1528), which he was writing in the second decade of the century, and Melencolia I, specifically "the deep frustration with geometry as a key to the problem" of how sense experience and images were related, Peter Parshall, "Graphic Knowledge: Albrecht Dürer and the Imagination," Art Bulletin, 2013, 95/3:393-410, p. 395. And (p. 406), "It seems that for Dürer the Meisterstiche represented an epistemological summa not only incorporating the terms of his investigations but also reflecting his ultimate view, namely, that geometry was insufficient as an answer."

6 Vnderweysung der Messung, mit dem Zirckel vnd Richtscheyt, in Linien, Ebenen vnnd gantzen corporen, unpaginated introduction. On Dürer's own copy of his text, which contains drawings and notes, see Noam Andrews, "Albrecht Dürer's Personal Underweysung der Messung," Word \& Image, 2016, 32/4:409-429. 


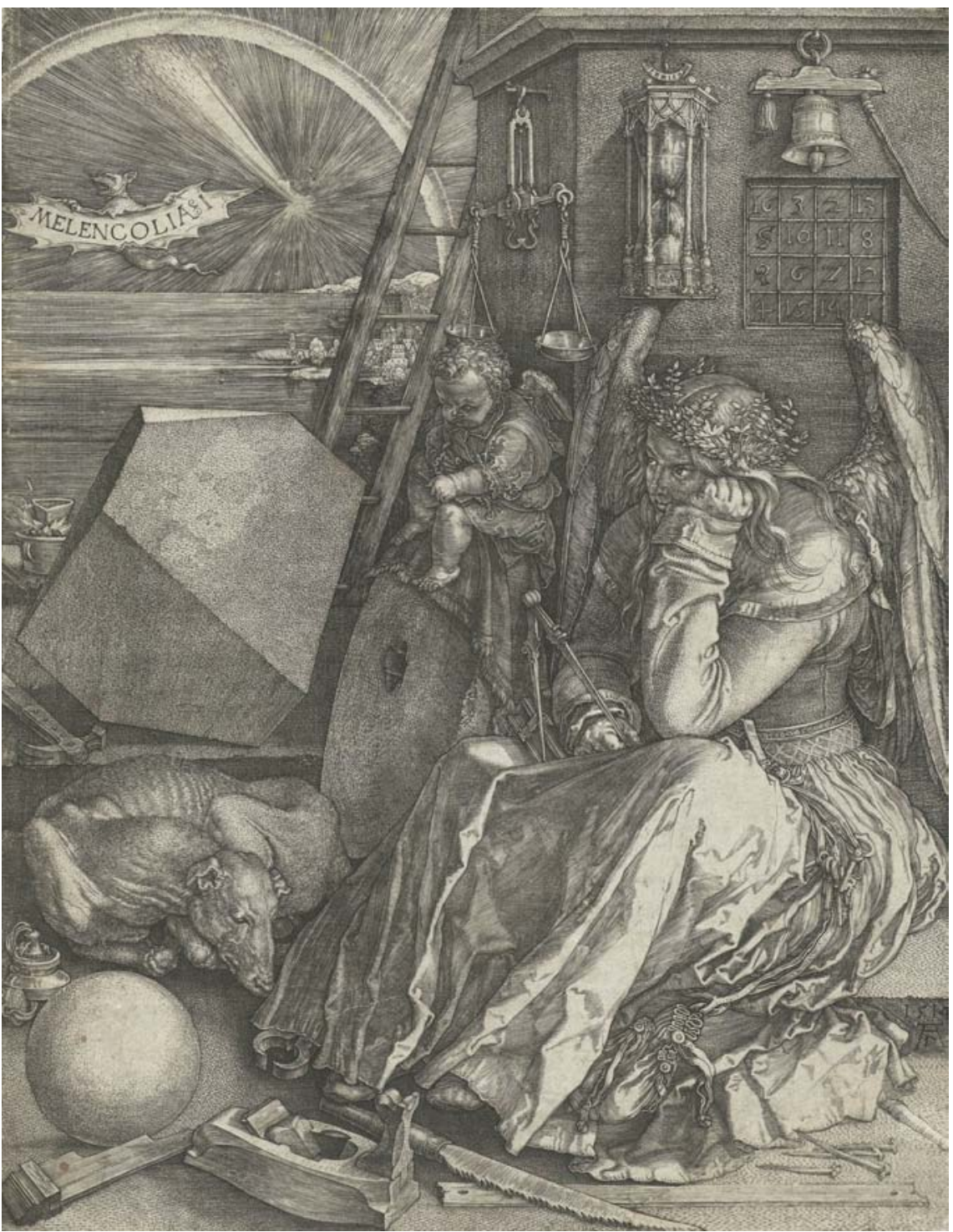

FIGURE 2 Albrecht Dürer, Melencolia I, 1514. Engraving, 23.9 $\times 18.5 \mathrm{~cm}$ RIJKSMUSEUM, AMSTERDAM RP-P-OB-11.705 
Geometry had long been endorsed as a divinely ordained undertaking. Kepler reminded his readers in 1599 that "The Creator, the true first cause of geometry ... as Plato says, always geometrizes." ${ }^{7}$ God the geometer was credited with the architecture of the cosmos and the inherent geometry of nature. The snowflakes that fell on Kepler's coat on the Charles Bridge, and inspired him to ask why they have six sides, prompted a disquisition on causes. God, Kepler writes, prescribes the laws of nature, and the plan of the creator is determinative. Ultimately, it is a formative faculty that accounts for the structures he observes. And this he qualifies in his conclusion: "The formative faculty of Earth does not embrace one figure: It is practiced and well versed in the whole of geometry" 8 Geometry, thus, offered a means of studying nature - God's handicraft - that could capture its manifold aspects. Nicolas of Cusa, recalling Protagoras's encouragement to study man as the measure of things, explains how that study is a vector to an understanding of God's thinking: "a human, by the nature of their sense perception, knowing that perceptible objects exist for the sake of perception, measures perceptible objects in order that, perceptually, they might be able to apprehend the glory of the divine intellect." ${ }^{9}$

The productive tension between the abstract, theoretical, and spiritual dimensions of early modern geometry (geometry as a branch of mathematical speculation) and the practical and material dimensions (geometry as, literally, the "measuring of the earth") is noteworthy. ${ }^{10}$ The dividing line between the high-minded principles and the manual craft of spatial measurement is not geometrical. Nature's geometry was complex, and practical applications of geometric reasoning abundant. Navigation, economic transactions, and surveying above and below the surface of the earth were structured by geometry as well. Geometry in the form of perspective, an abstraction of the visual field, enabled artists to raise their practice to the status of a liberal art, even as

$7 \quad$ Quoted by Samuel Y. Edgerton, The Mirror, the Window, and the Telescope. How Renaissance Linear Perspective Changed our Vision of the Universe (Ithaca-London: Cornell University Press, 2009), p. 1.

8 Johannes Kepler, The Six-Cornered Snowflake. A New Year's Gift, with an English translation in a dual language edition with various essays (Philadelphia: Paul Dry Books, 2010), p. 89 and passim.

$9 \quad$ Nicolas of Cusa, De beryllo, $\S 69$, as translated by Nelson, Disharmony of the Spheres (cit. note 1), p. 29.

10 On mining, geometria subterranea, see Thomas Morel, "De Re Geometria:Writing, Drawing, and Preaching Mathematics in Early Modern Mines," Isis, 2020, 111/1:22-45; and on fencing, see esp. Ken Mondschein, "The Number of Motion: Camillo Agrippa's Geometrical Fencing and the Enumeration of the Body," Journal of the Northern Renaissance, 2014, 6: http://www.northernrenaissance.org/issues/issue-6-2014/ (accessed 26 July 2020). 
artisanal practices materialized geometry. This is what makes Dürer's allegory so potent: manual or bodily frustration signals a mental confusion. Renaissance geometers were as likely to be material practitioners of geometric handiwork, as abstract thinkers demonstrating rational truths. The Nuremberg goldsmith Wenzel Jamnitzer's polyhedral study Perspectiva corporum regularium (1568) demonstrates a disciplined and playful engagement with the five Platonic solids, and these geometric bodies, artfully depicted in etchings by Joost Amman, are implausible forms that are also studies in light, shade, and modeling. ${ }^{11}$ Geometry offered the possibility of real allegories.

This special issue was born of a symposium on early modern geometries hosted by the Department of Art History at Northwestern University and The Newberry Library in Chicago, with support from the Myers Foundations and the Alice Kaplan Institute for the Humanities. The papers aimed to deconstruct the anachronistic notion that Dürer's use of geometry, for instance, represents an awakening of abstract rationality and theory separate from and master over mechanical practice. Its aim was to begin to reconstruct artisanal mathematical epistemologies developed and deployed by a range of visual artists and early modern 'scientists' alike, and to do so by way of printed texts. ${ }^{12}$ The selection of four papers that appear here take up the subject of early modern geometry and show, in disparate ways, what geometrical thinking amounted to. In geometrical practices of the early modern era we encounter the embodiment of cognitive and rational theories, and modes for structuring place and property; we find expressions of nature's formal powers. Geometry describes and it constructs, in the hands of Nature and man alike. The Euclidean practice of geometry always already involved figuration - aphorisms were translated into figures by students of geometry all along: geometry is a science of sense perception that requires tracing out figures, in order to comprehend the world and find a place in it.

11 "At the same time these playful constructions celebrate the technical skill of the artisan, they also illustrate Nature's metamorphic ability to construct an infinite variety of forms from these five basic elements, which, as Jamnitzer's introduction asserts, is paralleled by the creativity of the craftsman." See the entry by Kate Tahk in Dackerman (ed.), Prints and the Pursuit of Knowledge (cit. note 2).

12 The May 1482 publication in Venice by the German printer Erhard Ratdolt of Euclid's Elements (Liber elementorum in artem geometrie) has been called a hallmark in the history of textbook publication, and is one of the most famous books ever printed. Ratdolt's is a publishing feat that continues to amaze - not least for the technique Ratdolt devised for printing the diagrams. 
Rebecca Zorach's essay addresses geometry in nature and geometry in art in early modern Europe through the figure of the Swiss naturalist Conrad Gessner and his 1565 study of fossils in particular. "Stones, Snowflakes, and Insect Eggs: Conrad Gessner's Figura and Geometric Nature" examines how Nature creates geometric forms, a problem Kepler too grappled with, in the icy cold of Prague. Kepler's interest was in forms that fell from the heavens and Gessner turned his attention to things taken up from the ground, and both understood formative forces to operate geometrically. Zorach's essay also explores the concept of "figure" as a property of abstract geometry, of images, and of natural forms. Along with selected images, she studies texts ranging from theology to art theory to mineralogy and other branches of natural philosophy, tracing the changing relationship of geometry to human exceptionalism and human freedom as scientific study of the geometry of nature advances over the sixteenth and seventeenth centuries. Suzanne Karr Schmidt takes up practical geometry in the form of land surveying in her "Pfinzing and Friends: Surveying Culture in Renaissance Nuremberg." Paulus Pfinzing von Henfenfeld was a patrician merchant who developed and invented surveying tools, and publicized their use. In two anonymously published books from 1598-1599, Pfinzing entreated the well-educated to take up surveying and presented a summary of recent scholarship on geometric solids based on Albrecht Dürer and Wenzel Jamnitzer, among other luminaries. Karr Schmidt investigates the contradictory ways Pfinzing used his knowledge of surveying and familiarity with Nuremberg publishing to present the applied art of geometry as a gentlemanly pursuit.

The second pair of essays make broader claims for the stakes of early modern geometry. Raz Chen Morris cites Leon Battista Alberti, author of Della pittura (1435) as the founder of a "utopian moment," a philosophical and practical disposition fusing human ingenuity, geometry, and political harmony. "Geometry and the Making of Utopian Knowledge in Early Modern Europe" traces the outcome of this moment over the course of the sixteenth century, in the works of Johannes Kepler, and René Descartes, who reshaped utopian dispositions with new geometrical analyses of sight and light. Analyzing Kepler's Dioptrice and Descartes's scientific meditations on the rainbow in Les Météores, Chen Morris shows how these analyses are entwined with subtle political metaphors. It is with the help of a new mode of geometry that a utopian vision is projected by these early modern scientists. In "Johannes Kepler and Twenty-First-Century Science" Lawrence Lipking returns us to Kepler's On the Six-Cornered Snowflake (1611). In its search for the cause of a geometry inscribed in nature, an archetypal or divine mathematics, the little book follows in miniature the course of Kepler's epic quest for celestial designs, the geometrical patterns, such as his three great Laws, that shape the cosmos and underlie the harmony of the world. 
The plan of the snowflake, like that of the solar system, reflects the mind and hand of the Great Geometer, God. At the same time, The Six-Cornered Snowflake anticipates a major direction of twenty-first-century science. This essay is a historical meditation on the relationship between Kepler's geometrical ruminations and modern fractal geometry, a proposal to project early modern geometries into their futures. 